\title{
Correspondence
}

\section{Expressed Emotion and Relapse in Schizophrenia}

With reference to the correspondence under this heading (Journal, June 1986, 148, 741-742) neither Dr Leff nor Dr Vaughn was involved in any stage of the assessment and editing of the paper between receipt of the manuscript and publication.

Editor

\section{Deficits of Chronic Schizophrenia in Relation to Long- term Hospitalisation}

Sir: Mathai \& Gobinath's study (Journal, May 1986, $148,509-516)$ casts further doubt on the role of 'institutionalisation' in determining the course of chronic schizophrenia. We have argued (Abrahamson \& Brenner, 1978; Abrahamson, 1983) that the positive correlation between length of stay and negative handicaps characteristic of previous studies was a reflection of the inadequacy of a cross-sectional approach. A cohort of patients with negative handicaps which persisted largely unchanged through hospital courses of 30 years or more was mainly responsible for the positive correlations we obtained retrospectively, which were strikingly similar in pattern to those obtained by Wing \& Brown (1975).

It seems possible that Mathai $\&$ Gobinath have avoided this particular pit-fall because few such patients now exist in their long-stay populations or, more probably, because they were screened out by the diagnostic and exclusion criteria. It is notable that none of the patients were aged over 55 years and that only $8.8 \%$ of the NIMHANS and $18 \%$ of the $\mathrm{MH}$ long-stay populations were included. Whilst avoiding one source of bias others may have been introduced by the exclusion process, or submerged in the cross-sectional analyses. We found it revealing to relate the scores on disability scales to length of stay year-by-year rather than to longer time spans. In addition, despite their limitations, case-note studies provided an invaluable longitudinal dimension, the importance of which is underlined by prospective studies of long-term courses (Bleuler, 1978; Harding \& Strauss, 1985). The numbers in Mathai \& Gobinath's groups are sufficiently small for detailed case-note studies to be feasible for all the patients included and samples of those excluded.

The main impression from the Goodmayes study, which has been reinforced by continuing experience with some of the patients concerned, is of the individual consistency of courses. A longitudinal framework is therefore essential to do justice to social influences, which appear to operate within narrow, perhaps biologically determined, constraints over a very long time course. A much more complex explanation than either a disease process or a social model alone provides is likely to be required for the re-evaluation of 'institutionalisation'.

Goodmayes Hospital,

DAVID ABRAHAMSON

Barley Lane,

Ilford, Essex IG3 $8 X J$

\section{References}

Abrahamson, D. \& Brenner, D. (1978) A Study of the 'Old Long. stay' Patients in Goodmayes Hospital. Report to DHSS. London: DHSS.

- (1983) Schizophrenic deterioration: A discussion. British Journal of Psychiatry 143, 82-83.

BLEULER, M. (1978) The Schizophrenic Disorders: Long-term Patient and Family Studies. London: Yale University Press.

Harding, C. M. \& Strauss, J. S. (1985) The course of schizophrenia: An evolving concept. In Controversies in Schizophrenia (ed. M. Alpert) London: Guildford Press.

WiNG, J. K. \& BRoWN, G. W. (1970) Institutionalism and Schizophrenia. Cambridge: Cambridge University Press.

\section{The Northwick Park Study of First Episodes of Schizophrenia}

Sir: Hidden away in the four papers on first episodes of schizophrenia from Northwick Park (Journal, February 1986, 148, 115-143) is information of interest to psychogeriatricians. First, the inclusion of patients "aged between 15 and 70 years, with a first psychotic illness, not unequivocally affective", would suggest that British psychiatrists accept that schizophrenia can develop for the first time in patients over the age of $\mathbf{4 0}$ or $\mathbf{4 5}$. Second, Table I (page 116) shows that three patients were excluded as being outside the age range. Were any of these over the age of 70 ? Third, Table I (page 129) shows that 37 of $253(14.6 \%)$ patients were aged 40 or over on admission. The Table shows the expected excess of males over females for all ages, but does this relationship hold for the older age groups? Fourth, Table I 
(page 129) also shows that there was one patient aged 60-65 who was trial eligible, but not a trial entrant. Table I, (pages 122-123) shows that randomisation was applied to patients only between ages 15 and 59 . Why? Does this mean the researchers were reluctant to diagnose schizophrenia in a patient aged 60 or more?

\section{Severalls Hospital,} Colchester CO4 SHG

Peter S. Grahame

Drs Johnstone, Macmillian and Crow Reply

Sir: We limited our age range to $15-70$ years largely for practical reasons. Our collaborators like ourselves generally only see patients within that range and furthermore a study which involved a 2-year follow up while the patients continued on drug regimes with stated minimum doses would have been associated with additional difficulties in the very young and the elderly. The three patients excluded from the trial on the grounds of age consisted of a 14 year old male, a 71 year old female, and a 73 year old female. The 37 patients aged 40 or over on admission consisted of 22 females and 15 males. The trial eligible patient aged between 60 and 65 who was not a trial entrant was a 65 year old lady who did not wish to participate in the trial. She would have been very welcome to do so but her refusal meant that there was no-one over the age of 60 to be included in the randomisation process.

Eve C. JOHNSTONE

J. Fiona Macmillan T. J. CROW

Clinical Research Centre,

Watford Road,

Harrow, Middlesex HAI $3 U J$

\section{Alcohol Related Problems in Ethnic Minorities}

Sir: We read with interest Dr King's paper on at-risk drinking among general practice attenders (Journal, May 1986, 148, 533-540). We were interested to find that there were significantly more Irish and Scots among the at-risk drinkers but were surprised to note that no Asians seemed to fall into the at-risk group. This was in spite of the fact that $28 \%$ of the screened population had a country of birth outside the United Kingdom. We have recently looked at the differences in morbidity patterns between Asians and non-Asians with a diagnosis of alcoholic liver disease at the Royal Free Hospital (Banerjee et al, 1986). Our results showed that of the $\mathbf{8 5 2}$ biopsies performed showing alcoholic liver disease between January 1978 and November 1984, 58 (6.8\%) were from Asian patients. This is a higher percentage than one would expect when corrected for the percentage of Asians in the population.

Previous studies have suggested that there are differences in alcohol sensitivity between different ethnic groups (Chan, 1986; Ewing et al, 1974). In addition, it has also been shown that drinking patterns vary between different ethnic groups (Caetano, 1984). We suggest, therefore, that Asians are a high-risk group for alcohol related problems (Balaharan et al, 1984) and the apparent low incidence of alcohol related problems in surveys may be due to socio-cultural taboos which result in underreferral to the patient's local general practitioner.

ARPAN BANERJEE

S. S. VIRDEE

The Royal Free Hospital.

Pond Street, London NW3 2QG

\section{Reforences}

Balaharan, R., Bulusu, L., Adelsten, A. M. \& Shuxle V. (1984) Patterns of mortality among migrants to England and Wales from the Indian subcontinent. British Medical Journal 289, 1185.

Banezuez, A. K., Virdee, S. S. \& Deo S. I. (1986) Differences in morbidity/mortality patterns between Asians and non-Asians with a histological diagnosis of alcoholic liver disease (submitted for publication).

Caetano, R. (1984) Ethnicity and drinking in Northern California. A comparison among Whites, Blacks and Hispanics. Alcohol and Alcoholism 19, 31-44.

ChАN, A. W. K. (1986) Racial differences in akcohol sensitivity. Alcohol and Alcoholism 211, 93-104.

Ewing, J. A., Roure, B. A. \& Peluizari, E. E. (1974) Alcohol sensitivity and ethnic background. American Journal of Psychiatry 131, 206-210.

\section{Hypomania Following Cognitive Therapy}

Sir: We enjoyed reading the letter from Drs Hughes \& McKane (Journal, March 1986, 148, 344). They suggest that the patient we describe is typical of a bipolar affective disorder developing in middle life. However, continued assessments of this patient for two years after involvement in the research study have shown no further episodes of affective disturbance. This might be expected in a patient with an initial diagnosis of dysthymia, which in DSM-III terms is a low grade depressive disturbance that is rarely associated with bipolar affective disorder. We were also excited by their hypothesis that the filling in of numerous questionnaires may induce mania. An examination of the data from our study reveals 120 patient-years of questionnaire administration but no other case of mania has been found. Reluctantly, therefore, we had to abandon this hypothesis. We are left, therefore, with an isolated case of mania manifested towards the end of a programme of cognitive therapy. Although no case report proves a hypothesis, it is reasonable to conclude that the 